\title{
O desafio da gestão institucional para o desenvolvimento regional: a experiência do Instituto Federal Fluminense
}

\author{
José Luis Vianna da Cruz \\ Universidade Candido Mendes/Campos dos Goytacazes \\ Carla Nogueira Patrão Aquino \\ Universidade Candido Mendes/Campos dos Goytacazes
}

\section{Resumo}

O artigo apresenta, como questão central, a análise de uma experiência de criação de uma representação territorial no órgão máximo de Gestão do Instituto Federal de Educação, Ciência e Tecnologia - IF, baseada na articulação das escalas abrangidas por esse equipamento de Educação Profissional e Tecnológica - EPT, e realizada pelo IFFluminense, com sede em Campos dos Goytacazes/RJ. A experiência foi motivada pela constatação do desencontro entre a missão atribuída a esse novo formato de instituição de EPT, de ser um ator importante no desenvolvimento local e regional, uma vez que sua implantação seguiu critérios de interiorização e regionalização, em todo o território nacional, e a estrutura de gestão prevista nas normas e diretrizes que presidem a instituição. A fim de contribuir para o debate, traz uma abordagem teórica da relação entre território, desenvolvimento e escalas de ação institucional, e apresenta os IFs em sua condição de condutores de uma política nacional de base territorial. A análise da experiência, ainda que esta seja embrionária e restrita ao campo da gestão, pode contribuir para compreender a possibilidade, real e necessária, de se adotar arranjos escalares específicas nos processos pedagógico, administrativo e também de gestão, para que os IFs possam se aproximar cada vez mais da constituição enquanto atores relevantes nos processos de desenvolvimento local e regional.

Palavras-chave: Território. Desenvolvimento. Escalas. Educação Profissional.

\section{The challenge of institutional management for regional development: the experience of the Federal Fluminense Institute}

\footnotetext{
Abstract

This paper presents, as its core issue, an analysis of an experience on working out a territorial representation in the higher management body of the Federal Institute of Education, Science and Technology, based on the articulation of the scales covered by the TPE-Technical and Professional Education unit named IFFluminense, with headquarters in
} 
Campos dos Goytacazes/RJ. The experience was motivated by the fact that there is a mismatch between the mission attributed to this new format of TPE institution, which is to act as an outstanding actor in local and regional development, since its implantation followed criteria of regionalization and hinterland driving, throughout the national territory, and the management structure provided for in the norms and guidelines that preside the institution. In order to contribute to the debate, it presents a theoretical approach to the relationship between territory, development and scales of institutional action, and presents the Federal Institutes (FI) in their capacity as partners in a territorial-based national policy. The analysis of the experience, even though it is embryonic and restricted to the field of management, can contribute to understand the real and necessary possibility of adopting specific scalar arrangements in the pedagogical, administrative and management processes, so that Fls can fulfill their mission as relevant actors in local and regional development processes.

Keywords: Territory. Development. Scales. Professional Education.

\section{El desafío de la gestión institucional para el desarrollo regional: la experiencia del Instituto Federal Fluminense}

\section{Resumen}

El artículo presenta, como cuestión central, el análisis de una experiencia de creación de una representación territorial en el órgano máximo de Gestión del IF - Instituto Federal de Educación, Ciencia y Tecnología, basada en la articulación de las escalas cubiertas por ese equipo de EPT-Educación Profesional y Tecnológica, y realizada por el IFFluminense, con sede en Campos dos Goytacazes / RJ. La experiencia fue motivada por la constatación del desencuentro entre la misión atribuida a ese nuevo formato de institución de EPT, de ser un actor importante en el desarrollo local y regional, una vez que su implantación siguió criterios de interiorización y regionalización, en todo el territorio nacional, y la estructura de gestión prevista en las normas y directrices que presiden la institución. A fin de contribuir al debate, trae un enfoque teórico de la relación entre territorio, desarrollo y escalas de acción institucional, y presenta los Institutos Federales en su condición de conductores de una política nacional de base territorial. El análisis de la experiencia, aunque ésta sea embrionaria y restringida al campo de la gestión, puede contribuir a comprender la posibilidad, real y necesaria, de adoptar arreglos escalares específicos en los procesos pedagógico, administrativo y también de gestión, para que los IF puedan ser aproximar cada vez más la constitución como actores relevantes en los procesos de desarrollo local y regional.

Palabras clave: Territorio. Desarrollo. Escala. Educación Profesional.

\section{Introdução}

Este artigo apresenta uma experiência ${ }^{1}$ de gestão do Instituto Federal de Educação, Ciência e Tecnologia Fluminense - IFFluminense, em 2015, de configuração de uma escala específica, a partir do conceito de Núcleo, objetivando a reestruturação do seu principal órgão colegiado decisório. Essa construção busca atender, no plano da gestão, ao desafio posto pela missão institucional dos IFs, de

\footnotetext{
${ }^{1}$ O presente artigo foi publicado nos Anais do XVII ENANPUR (São Paulo - 22 a 26/05/2017), sendo que a atual versão já incorporou as contribuições oriundas do evento e posteriores reflexões dos autores, com modificações no texto, inclusive no título.
} 
se constituir em um agente do desenvolvimento local/regional nos territórios onde se instalam. O principal objetivo é contribuir para a reflexão acerca das possibilidades de aprofundamento das relações entre uma instituição de educação com as especificidades dos IFs e as demandas da sociedade onde opera, no sentido do fortalecimento das potencialidades locais e regionais para o desenvolvimento. Isso implica na construção de escalas específicas de gestão, sem negar as construções formais existentes, mas, contudo, reconhecendo que, dados os seus limites herdados da experiência dos Centros Federais de Educação Tecnológica Cefet e das Escolas Técnicas, carregam obstáculos à missão que lhe é atribuída. Buscar uma ou outra escala depende dos objetivos e dos problemas que se planeja enfatizar, decorrentes da leitura que se faz das relações entre território, desenvolvimento e o IF. Não é possível avaliar, de forma conclusiva, tal experiência, por ainda carecer de maior decurso de tempo. Por isso, o artigo se limita a apresentar os elementos presentes na construção da experiência analisada, no sentido de defender a necessidade desse esforço de "trânsito" escalar na gestão voltada para as demandas territoriais ante o desafio de compreender a realidade em que a instituição está inserida e aproximar sua atuação aos princípios e diretrizes a ela vinculados.

Dados os limites acima apontados, o trabalho justifica-se por duas razões: primeiro, o fato de estar em curso um debate acerca da dinâmica regional do país em que a tradicional divisão macrorregional vem perdendo sentido analítico nas últimas décadas; e segundo, porque tais mudanças estão na base das questões associadas ao processo de consolidação das instituições federais de educação profissional, na sua missão de contribuir para o desenvolvimento regional. $O$ compromisso estatutário, normativo, como o desenvolvimento regional, é algo inédito na política de educação no Brasil, o que torna duplamente complexo o conjunto de desafios: comprometer-se com o desenvolvimento regional num contexto de ausência de efetiva política de desenvolvimento regional no âmbito de um projeto de desenvolvimento nacional.

A problemática aqui levantada considera que, se os IFs foram concebidos e estruturados como uma política educacional centrada nas relações com o território, pressupõem-se mudanças nas formas tradicionais de concepção e operação da gestão institucional, herdadas das escolas técnicas e dos CEFET, nos quais o compromisso com o desenvolvimento do território estava ausente. Se, de um lado, há referências normativas para que o IF cumpra sua missão, de outro, a realidade empírica traz desafios postos pela necessidade de ajustes ao concebido. Uma das mudanças normativas introduzidas na gestão dos IFs foi a constituição de diversos colegiados em sua estrutura, dentre eles, o Conselho Superior - Consup, instância máxima de deliberação. No entanto, percebe-se que a formação original do Consup do IFFluminense não traduzia a angulação no sentido do território. Sua composição, com base no estatuto da época de criação dos IFs, não incorporava a representação dos diversos campi espalhados pelos diversos municípios, micro e mesorregiões do Estado do Rio de Janeiro - ERJ, não abarcando as características profundamente distintas entre os territórios dos campi².

\footnotetext{
${ }^{2} \mathrm{O}$ IFFluminense possui 13 campi em 04 das 08 mesorregiões fluminenses: 06, no Norte Fluminense; 04, no Noroeste Fluminense; 01, nas Baixadas Litorâneas e 02, na Região Metropolitana do Rio de Janeiro.
} 
Quais seriam os elementos a serem considerados, no plano da gestão institucional, na sua instância máxima de decisão, para que o IF esteja à altura do desafio da contribuição possível ao desenvolvimento regional?

Assim, a implementação de uma política pública, sob diretrizes nacionais, como é o caso apresentado neste artigo, requer ajustes para sua efetividade, na medida em que há variáveis locais e regionais que interferem na aproximação entre o IF e o território. Assim sendo, o artigo trata das relações entre os IFs e o território, na perspectiva do desenvolvimento local e regional, exclusivamente no plano da gestão, na constituição do seu Consup, por compreender que esta é uma instância estratégica e condição fundamental para implantação da sua missão comprometida com o desenvolvimento. Para que isso se realize, considerando-se que o IFFluminense compreende 13 campi, espalhados por regiões tão diversas, desde a região menos desenvolvida do Estado - a Noroeste Fluminense - passando pela região do petróleo - o Norte Fluminense - e pela região turística, também beneficiada pela indústria do petróleo - a Baixadas Litorâneas - até a Região Metropolitana da capital, é necessário que esta diversidade esteja representada na sua instância máxima de decisão. É o que será trabalhado neste artigo, tendo como objeto a experiência do IFFluminense.

Serão confrontadas a problemática da dinâmica regional brasileira, a dinâmica da ação social sobre o território e a experiência do IFFluminense como um esforço inicial de enfrentamento do desafio da sua missão em relação ao desenvolvimento regional, no plano da estrutura de decisões de gestão.

O artigo está organizado em três partes, além da Introdução e das Considerações finais. Na seção 2, a relação entre território e desenvolvimento será abordada. A seção 3 aponta que as estratégias territorializadas de desenvolvimento passam pela definição do foco adequado em que os fenômenos serão melhor analisados, a partir do conceito de escala. A seção 3 apresenta as características dos IFs, a partir dos seus aspectos identitários. Ao final, apresenta-se a experiência da gestão do IFFluminense propriamente dita, corroborando a ideia de que são possíveis e necessários outros enfoques escalares na atuação institucional.

\section{A relação entre território e desenvolvimento}

O debate sobre a temática do desenvolvimento é permeado por posicionamentos conceituais diversos, na medida em que desenvolvimento constitui um processo multifacetado. É, pois, político, econômico, social e cultural, tendo a sociedade como seu lócus.

Numa leitura histórica, é importante apontar dois movimentos imbricados que marcaram a realidade brasileira a partir do século $\mathrm{XX}$ : o processo de industrialização e a dinâmica regional.

A segunda metade do século XX foi marcada por ciclos de expansão e de crise na economia brasileira. A implantação da indústria de base, nos anos 19301950; e o crescimento da indústria de bens de consumo no período de 1953-1961, decorrentes, principalmente, dos investimentos do Plano de Metas, promoveram uma forte concentração econômica no eixo Rio de Janeiro-São Paulo. As decisões relativas à localização dos grandes empreendimentos eram pautadas na relação 
custo-benefício, ou seja, em maior rentabilidade, priorizando as economias externas existentes nesse eixo territorial.

Nos anos 1960, agravaram-se os problemas econômicos, com acirramento de conflitos e dificuldades na governabilidade do País, culminando com o Golpe de 1964. A segunda fase de expansão foi na década de 1970, marcada por expressivos investimentos do Estado durante o II Plano Nacional de Desenvolvimento que contemplaram diversas regiões. Nesse momento, o apoio governamental incentivava a desconcentração regional, mas com a mesma lógica anterior, a de atender aos interesses empresariais.

Os anos 1980, como amplamente registrado, ficaram conhecidos na literatura como a década perdida. O crescimento inexpressivo ainda persistiu na década de 1990, sob o impacto das políticas neoliberais e do aumento da dívida pública.

A retomada do crescimento econômico data de 2004, com a inserção externa mais favorável da economia brasileira, beneficiada pela elevação dos preços das commodities. Analisando o período de 2003 a 2010, Bacelar (2013) argumenta que essa retomada rompeu com o padrão de crescimento dominante no século $\mathrm{XX}$, pois possibilitou o aumento do ritmo de crescimento da renda dos "extratos que vivem com renda menor" (Ibid., p. 42). E, ainda, provocou impactos regionais diferenciados, favorecendo, em especial, as regiões Norte e Nordeste do País, também influenciadas pelas políticas governamentais que beneficiaram a renda das famílias. No entanto, mesmo com os avanços, o País ainda apresenta entraves estruturais, não evoluindo, nesse período recente, na implementação de um planejamento nacional para o desenvolvimento regional.

O Brasil apresentou, a partir da segunda metade do século XX, mudanças no padrão locacional das atividades econômicas, com relativa desconcentração industrial e forte expansão das fronteiras agropecuária e mineral. No centro da desconcentração regional, a diferenciação econômica intrarregional foi acentuada, com o surgimento de sub-regiões detentoras de elevado dinamismo, constituindo "ilhas de prosperidade", ao lado de espaços sub-regionais com baixo dinamismo no interior das cinco macrorregiões brasileiras (PACHECO, 1998 apud SIQUEIRA, 2010).

Um dos fenômenos resultantes dessa desconcentração e da influência de ciclos de retração e de deseconomias de aglomeração é a interiorização da atividade econômica, com o fortalecimento das cidades médias. Estas novas cidades assumiram também a função de diques de contenção do fluxo migratório para as metrópoles (PIQUET, 2007).

Em relação ao processo industrial brasileiro, Diniz (2006) aponta uma combinação de quatro tendências: a) perda relativa da importância do eixo dinâmico Rio de Janeiro-São Paulo em função das deseconomias de aglomeração; b) concentração relativa das indústrias intensivas em tecnologia entre o centro de Minas Gerais e o nordeste do Rio Grande do Sul (polígono industrial); c) deslocamento das indústrias tradicionais para o Nordeste; d) expansão de atividades industriais ligadas às fronteiras agropecuária e mineral nas regiões Centro-Oeste e Norte do País.

Todavia, essa desconcentração não significou a desindustrialização do Estado de São Paulo, uma vez que a relativa maior participação de outras regiões do País aconteceu como apêndice à indústria paulista, mediante a complementaridade 
entre a indústria paulista e aquela instalada nas demais regiões brasileiras (SIQUEIRA, 2010).

Como resultado dessa dinâmica regional, mesmo com forte concentração no Sudeste e no Sul, há formação de expressivo número de áreas produtivas em diversos setores, revelando um país integrado-fragmentado simultaneamente (PACHECO, 1998 apud DINIZ, 2006). O processo de desenvolvimento brasileiro manteve a reprodução das profundas desigualdades socioterritoriais, em consequência do descompasso entre o investimento para atender ao capital e aqueles contabilizados como investimento em equipamentos sociais.

Bacelar (2013) relaciona as heranças mais importantes oriundas do processo brasileiro de ocupação territorial: forte concentração nos espaços litorâneos; diversidade e desigualdade regionais.

Apenas como registro, vale destacar as análises para o período pós-2010 (DINIZ, 2012; SIQUEIRA, 2013), que apontam para uma relitorialização e uma reconcentração regional da atividade econômica, isto é, uma regressão em relação à desconcentração e à interiorização que vinha acontecendo e que se expressa pela reconcentração do dinamismo na faixa litorânea brasileira em função dos investimentos realizados e projetados.

Assim, ao abordar a temática do desenvolvimento, estabelece-se uma conexão com a sua dimensão territorial, pois é no território que as relações socioeconômicas e culturais efetivamente se fazem presentes. Acerca do conceito de território, recorre-se a Cruz (2007), que articula o conceito de espaço como ambiente construído, fundamental para a produção e reprodução social e, por isso, "elo entre espaço e sociedade" e "relações entre território e ação". Nas palavras de Santos (1997), "[o espaço] é o ambiente construído pelos objetos fixados no espaço pela ação de produção e reprodução social". Ambiente que contém heranças, conflitos e representações simbólicas, ao mesmo tempo em que é recurso e campo de possibilidades.

Essae espaço construído não é harmônico, é complexo e conflituoso, pois há formas diferenciadas de reprodução social e é marcado por um campo de disputas, decorrentes do poder das forças sociais sobre os recursos do território, na medida em que a apropriação dos seus elementos constitutivos permite a existência de relações sociais desiguais.

O território contém o prático-inerte, é herança e patrimônio, que constituem seus recursos (ambiente construído, forças produtivas e relações sociais). Esses recursos são objeto de luta pela sua apropriação por parte de diferentes grupos sociais. Dessa luta dependem os recursos que serão privilegiados, as ações que serão desenvolvidas, quem perde e quem ganha, quais os produtos dessa ação, sua direção e sentido. A natureza do desenvolvimento depende de quem se apropria dos recursos territoriais e de qual direção e uso se dá aos mesmos. Isso depende de articulação de grupos e de escalas, de projetos e de agentes, sem perder de vista a hegemonia dos interesses econômicos (Ibid.).

Não é demais reafirmar que as desigualdades são inerentes ao capitalismo

Isso implica que o capitalismo tem de preparar o terreno para uma expansão do produto e um crescimento em valores reais (e, eventualmente, atingí-los) pouco importam as consequências sociais, políticas, geopolíticas ou ecológicas. (HARVEY, 1992, p. 166). 
Para Lefebvre (1974 apud BRANDÃO, 2014a, p. 18), "as classes sociais vivenciam e produzem o espaço em condições de profunda desigualdade". Contribuição importante apresenta Harvey (1973 apud BRANDÃO, 2014a, p. 19) quando argumenta que "partindo de uma análise das relações entre processos sociais e forma espacial, coloca[-se] ênfase nas lutas que se travam entre as frações do capital e entre este e o trabalho".

Ainda em relação a aspectos que denotam a não homogeneidade das relações no território, Brandão (2012) convida, em sua análise, a olhar criticamente a ideia que "paira no ar" de que "estaríamos vivendo em uma comunidade, não em sociedade" (Ibid., p. 183); o que, temerosamente, poderia nos levar a compreender o espaço social como ambiente harmônico, sem os conflitos inerentes ao sistema capitalista, fazendo crer na capacidade empreendedora e solidária de uma comunidade, instalando sobre esta a total responsabilidade pelo seu desenvolvimento.

A diferença entre espaço e território é enfatizada por Raffestin (1993), sendo o primeiro um estágio que antecede a existência do segundo

o território se forma a partir do espaço, é o resultado de uma ação conduzida por um ator sintagmático (ator que realiza um programa) em qualquer nível. Ao se apropriar de um espaço, concreta ou abstratamente [...] o ator territorializa o espaço. (RAFFESTIN, 1993, p. 143).

Para esse autor, essa apropriação do espaço, sua "territorialização" revela relações marcadas pelo poder. $\mathrm{Na}$ definição de qualquer território, a interdependência e a inseparabilidade entre a materialidade (natureza) e o seu uso (ação antropogênica) devem ser levadas em conta (SILVEIRA, 2009).

Santos (2008) também chamou atenção sobre a distinção entre território e espaço ao definir território como um recorte do espaço, sinônimo de espaço habitado, contendo múltiplas relações, redes e fluxos. O que distingue o território do espaço é o seu uso. É, pois, o uso deste que nos interessa, mais do que o território em si mesmo. Ainda ressalta que, ante o cenário global, o território pode ser formado de lugares contíguos e lugares em rede. E, para isso, incorpora a ideia de verticalidade e horizontalidade, como um novo funcionamento social do território. A verticalidade formada por relações, na acepção de pontos de uma rede, mais distantes uns dos outros, ligadas "por todas as formas e processos sociais" (Ibid., p. 139) . E a horizontalidade constituída por lugares vizinhos, contíguos no território. Portanto, diferentes usos do território coexistem e, assim, desenvolvimentos desiguais.

As diversas abordagens sobre território apresentadas evidenciam a importância de se entender o ambiente construído, as possibilidades de uso inerentes ao espaço social e a relação território-ação, permeada por disputas de poder, para compreender a dimensão territorial do processo de desenvolvimento. No entanto, não deve ignorar a complexidade que o mesmo abarca, a dialética da realidade concreta, pois, por um lado, se a mundialização mostra sua força no território, por outro, este território pode criar sinergias. Assim, a importância de perceber as múltiplas escalas existentes no território.

É nessa complexidade que deve ser trabalhada a inserção de um equipamento público educacional com as especificidades de um IF. Deve haver uma 
correspondência entre a diversidade dos interesses em disputa no território e sua representatividade na estrutura de gestão do IF, uma vez que, para cumprir sua missão, deve haver uma permeabilidade à discussão democrática sobre as prioridades territoriais, entre a instituição e os atores locais/regionais.

\section{Em busca de um enfoque multiescalar}

Há certo consenso de que o processo de globalização implicou, ao mesmo tempo, uma padronização do consumo, da cultura, da economia, da política, simultaneamente a uma fragmentação dos territórios. Há uma grande heterogeneidade quanto a oportunidades e riscos para as diferentes localidades. Essa compreensão, combinada com a de território entendido como espaço construído por relações sociais conflituosas e, portanto, com possibilidade de diferentes usos, diferentes formas de reprodução social, de apropriação dos recursos e poder, mostra a imperativa necessidade de uma visão multiescalar para captar a complexidade e a heterogeneidade dos diversos territórios habitados em um país continental como o Brasil, para construção de estratégias de desenvolvimento.

O espaço e o território comportam diversas escalas de ação, como local, regional, nacional e global. As escalas são produzidas pela ação articulada dos atores. Segundo Brandão (2004a, p. 60), "um problema pode se manifestar em uma escala, mas ter sua determinação em outra”, ou, pode acontecer que "os instrumentos de intervenção sobre uma realidade localizada podem estar em outra escala espacial, arena política, nível de governo, instância de poder”.

A escala é o foco dado na lente. Pensar as estratégias territorializadas de desenvolvimento passa, necessariamente, por definir qual o foco adequado em que os fenômenos serão melhor percebidos e que medidas e ações serão implementadas a partir daquele prisma de observação. Nesse contexto, Brandão (2012) traz para o debate a crítica à ideia bastante generalizada, de predomínio da bipolaridade das escalas espaciais, ou seja, existiriam apenas o local e o global, eliminando-se as escalas intermediárias. O autor reafirma a necessidade de se pensar em outras escalas para análise da dimensão espacial do desenvolvimento, em especial a nacional. Ingenuidade é imaginar que uma região possa sozinha gerar um processo de desenvolvimento, sem levar em consideração as condições supralocais e a interligação entre estruturas, ações e decisões que articulam as diversas escalas, e determinam as formas concretas, locais, de manifestação.

A escala nacional envolve diversos instrumentos de regulação, que vão desde o controle sobre os preços até a capacidade de gastos públicos. Estes formam a base territorial nacionalizada que fornece as condições para funcionamento do sistema capitalista. Harvey (1992) e Brandão (2012) reforçam a ideia de que para o sistema capitalista encontrar as condições de ordem para funcionar é necessário que o Estado seja responsável pelas políticas macroeconômicas. Nesse sentido, o poder soberano do Estado Nação deve ser preservado para a definição de estratégias de desenvolvimento, considerando a dimensão política que cabe exclusivamente à escala nacional.

Brandão (2014a) ressalta a necessidade de se qualificar a natureza da escala nacional, no sentido de sua autonomia. Inspirado em Celso Furtado, ele afirma que é 
necessário "sempre se questionar se esse sistema nacional estaria ou não a serviço de alternativas mais autônomas e soberanas" e

sobre a escala nacional no Brasil caberia questionar qual o grau de autonomia de decisão desse território, neste momento em que o país segue um percurso de especialização regressiva, com concentração de estrutura produtiva na oferta de commodities de baixa elaboração e na exploração de recursos naturais. (Ibid., p. 32).

Em um país heterogêneo como o Brasil, pensar uma proposta monoescalar é ignorar os conflitos, as disputas de poder, os centros de decisão, as questões estruturais de nossas desigualdades sociais. É também propagar uma visão ufanista do local, em que ao local cabem as respostas para superação do quadro de atraso estrutural e de subdesenvolvimento que modela a sociedade, cindida entre uma minoria com uma colossal concentração de riqueza e renda e uma expressiva maioria de não cidadãos a quem falta o acesso a um conjunto de direitos de várias naturezas. O local contém os conflitos de interesses e as contradições que o país possui, além de ser altamente vulnerável às movimentações nacionais e internacionais que interferem na economia e no desenvolvimento.

O grande desafio é tratar a diversidade regional brasileira como estratégia importante para "um desenvolvimento regionalmente harmônico", como afirma Bacelar (2009). É fundamental discutir a espacialidade dos problemas e implementar políticas que levem em conta a escala específica destes problemas e de suas implicações em outras escalas, mas dentro de um "contexto em que esteja presente um projeto nacional de desenvolvimento” (BRANDÃO, 2004b, p. 10).

A proposta multiescalar defendida por Brandão pode ser melhor compreendida quando este discorre sobre uma ação que busca soluções de âmbito regional, por meio de parcerias intermunicipais, com possibilidades reais de êxito

a ação supralocal geralmente pode lograr grande êxito em aumentar o poder de diálogo, pressão e negociação vis-à-vis ações isoladas dos municípios de determinada região, contribuindo para aumentar a acessibilidade a outras escalas espaciais e outros níveis de governo. (BRANDÃO, 2012, p. 208).

A ação que articula as escalas é desafiadora e complexa, na medida em que se faz necessário assegurar o diálogo, enfrentar a comodidade proporcionada pelas virtudes do lugar, articular em diferentes centros de decisão, para possibilitar a construção de uma agenda de ações articuladas no sentido do desenvolvimento regional. Brandão (Ibid., p. 210) classifica esta proposta de transescalar, na medida em que se estabelece a partir de relações horizontalizadas (na mesma escala) e verticalizadas (escalas abaixo e acima daquela em que se implementa a política) e que possibilita "cortes oblíquos e transversais nas diversas políticas públicas, atravessando-as, rearticulando-as [...] para realizar sua síntese em uma política de desenvolvimento que alargue os horizontes de possibilidades".

É importante destacar, a partir do reconhecimento positivo das heterogeneidades produtivas, sociais e regionais e do papel das escalas espaciais, que a "regionalização do território deve partir das dimensões de homogeneidade e polarização para se construir a escala de ação" (DINIZ, 2006, p.5). 
Reforça-se a importância de ações multiescalares que respondam aos problemas concretos, a partir da compreensão deste território que é singular, com vínculos para fora e para dentro de seu espaço e constituído por forças produtivas e relações sociais conflituosas. A partir desta concepção teórico-conceitual, e considerando o propósito deste artigo, será trazida para análise uma experiência de gestão do IFFluminense baseada em uma construção própria de escala no enfrentamento dos desafios institucionais para uma ação territorial voltada ao desenvolvimento.

\section{Procedimentos metodológicos}

O referencial apresentado anteriormente nos oferece as categorias analíticas que orientaram a abordagem sobre a experiência de gestão ora apresentada. São elas: a relação entre território e desenvolvimento e o conceito de escalas para implantação de uma política pública.

Em se tratando de uma tipologia institucional, recorreu-se à legislação, aos documentos oficiais elaborados pelo Ministério da Educação, como também à entrevista concedida pelo Ministro da Educação da época da promulgação da Lei N. ${ }^{\circ}$ 11.892/2008, que instituiu os IFs, para apresentar os quatro aspectos identitários selecionados para a abordagem aqui apresentada.

As informações e os dados relativos à experiência de gestão do IFFluminense propriamente dita foram levantados no site institucional, junto aos documentos divulgados pelo Consup, como estatuto, regimento interno, resoluções e atas das reuniões do colegiado, que permitiram pesquisar a composição do conselho antes e depois da adoção do conceito de núcleo que subsidiou a escolha dos conselheiros, bem como os debates realizados durantes as reunióes do colegiado com tal finalidade.

\section{Construindo uma configuração escalar na gestão de uma política pública na educação profissional e tecnológica}

Esta seção desenvolve-se em duas etapas: primeiro, trata da Lei N. 11.892/2008 de criação dos IFs, a partir de seus aspectos identitários, que provocaram a percepção de gestores da reitoria, de um descompasso entre as suas atribuições e o aparato normativo-institucional do IFFluminense e descritas nas normativas e regulamentos "interna corporis", como a constituição do Consup. Assim, sem óbices legais, a partir desta apreciação e considerando sua missão e propósitos, a gestão desencadeou mudanças na composição deste Conselho, no biênio 2015-2016, resultando em uma experiência que será apresentada nesta seção.

Aspectos identitários dos Institutos Federais de Educação, Ciência e Tecnologia

As políticas do governo federal dirigidas à EPT, dentre as quais a criação dos IFs e a expansão da Rede Federal, configuraram ações cuja relevância do ponto de vista da política pública possibilitaram projetar avanços sociais a partir de 2003. É interessante recuperar os períodos iniciais dos anos 2000 ou, até mesmo, retroceder um pouco mais, para descrever o contexto onde se inseriam as políticas educacionais, para entender a natureza desta "guinada". 
No contexto brasileiro, os anos 1990 foram marcados pelo avanço do papel do Estado na desregulação, liberalização e adoção de políticas fiscais ortodoxas, em detrimento da responsabilidade pela gestão e custeio das políticas públicas. Acrescentados os efeitos do processo de globalização, redundaram no aumento da pobreza e das desigualdades sociais; na queda dos investimentos de longo prazo; na abertura comercial e financeira; nas privatizações extensivas; na flexibilização das leis trabalhistas; na restrição da ação do Estado em áreas sociais e na valorização do setor privado em relação à oferta de serviços à população (PIQUET, 2007; ORTIGARA, 2014). Nesse período, as políticas governamentais voltadas para a educação profissional priorizaram a expansão das instituições privadas, reforçando o traço conservador do desenvolvimento brasileiro, ao negligenciar a importância dos equipamentos públicos no atendimento das demandas sociais.

A ascensão de um governo liderado por um partido identificado, programaticamente, com o enfrentamento das questões sociais, implicou em um novo ordenamento normativo que criou as condições legais e institucionais para implementar, a partir de 2003, uma nova política pública para a EPT. Nos documentos formais, registra-se o caráter estratégico e inovador dessas políticas.

\begin{abstract}
De 2003 a 2010, foram autorizadas 214 novas unidades federais, ou seja, teve-se realizado uma ampliação de $150 \%$ do parque federal de educação profissional e tecnológica em apenas oito anos. (BRASIL, 2007b, p. 32). $[\ldots]$

A implantação dos Institutos Federais de Educação, Ciência e Tecnologia constitui-se em uma das ações de maior relevo do Plano de Desenvolvimento da Educação - PDE, na medida em que tornará mais substantiva a contribuição da rede federal de educação profissional $e$ tecnológica ao desenvolvimento socioeconômico do conjunto de regiões dispostas no território brasileiro (Ibid., p. 33) (Grifo dos autores).

Visão sistêmica da educação, território e desenvolvimento se fundem nos IFET $^{3}$ de maneira plena. Uma rede com 354 unidades não pode manter as características do período anterior. A maturidade da rede federal de educação profissional e tecnológica e a escala e a dispersão das unidades por todas as mesorregiões do País exigem um novo modelo de atuaçãa, que envolva o desenvolvimento de um arrojado projeto político-pedagógico. (BRASIL, 2007a, p.1) (Grifo dos autores).
\end{abstract}

A partir de uma abordagem que destaca a importância da regionalização da política de EPT como aspecto determinante para a institucionalização dos IFs, é frutífero recorrer a Brandão (2014b), sobre a nova Política Nacional de Desenvolvimento Regional - PNDR. Mesmo reconhecendo que diversos aspectos dessa política não avançaram, identificou progresso no que se refere ao combate às desigualdades regionais, com a implementação de políticas nacionais de cunho territorial, orientadas pelos princípios da transversalidade, multidimensionalidade e transescalaridade. Assim sendo, a criação dos IFs deve se juntar a este conjunto de "verdadeiras políticas regionais implícitas" (Ibid., p. 339); neste sentido, cabe aos IFs buscar fortalecer a dimensão regional das políticas nacionais e estabelecer o diálogo perene com outras políticas nacionais setoriais, na construção de elos intersetoriais.

Este artigo parte da conceituação de institucionalidade para distinguir o que são os IFs. Bucci (2014) apresenta o teórico do direito italiano do começo do século

\footnotetext{
${ }^{3}$ Os primeiros documentos na época faziam referência aos Institutos Federais como IFET.
} 
$X X$, Santi Romano, que define o processo de institucionalização como despersonalização e formalização de algo com base na regra jurídica, ou seja, uma ideia, a iniciativa de uma pessoa, de um político, de um gestor público ou de um grupo de pessoas, que vai se transformar, pelos caminhos processuais pertinentes, em algo mais perene, mais permanente, impessoal, que não dependerá mais de quem o originou. No caso dos IFs, a institucionalização se realizou por meio de uma lei federal que representa a valorização da EPT, da formação profissional das pessoas e do potencial destas instituições no processo de interiorização e de combate às desigualdades regionais. A fala do ministro da Educação à época, Fernando Haddad, em entrevista à Empresa Brasileira de Comunicações, ilustra a singular concepção dos IFs e da política de expansão.

Nós vamos desinchar as regiões metropolitanas e fazer crescer, com qualidade, as cidades de 100 a 300 mil habitantes, de 100 a 500 mil habitantes, ou seja, nós vamos descentralizar o desenvolvimento, colaborando com os grandes centros que vão se beneficiar por essa fixação do jovem no interior do país. Nós temos que continuar esse processo, para que a juventude tenha a oportunidade, se não na sua cidade, próximo à sua cidade, sem ter que se deslocar para as capitais para ter acesso à educação profissional e educação superior. (HADDAD, 2011).

Assim, a lei definiu as diretrizes, os princípios e a organicidade dos IFs. A criação dos IFs foi o passo inicial no sentido de institucionalização da ideia original. Entretanto, essas instituições precisam adquirir materialidade e efetividade e, para isso, é preciso que a dinâmica institucional, as relações estabelecidas, a comunidade acadêmica, inclusive a comunidade externa que impacta e é impactada por ela, enfim, todos esses atores, desejem e se comprometam a militar para alcançar os objetivos e finalidades institucionais propostos. Os aspectos que expressam a identidade institucional ganham relevância neste artigo, por isso, destacam-se quatro aspectos.

$O$ primeiro refere-se à força do compromisso dos IFs com 0 desenvolvimento. Atuar com ênfase no desenvolvimento local e regional ${ }^{4}$, sem perder a dimensão do contexto nacional, é preceito fundante dos Institutos. Analisando a lei de criação dos IFs e o documento que tece comentários e reflexões sobre a mesma (SILVA, 2009), percebe-se que há uma concepção implícita de desenvolvimento que reforça a centralidade na inclusão, pois reúne elementos convergentes para a questão social e o desenvolvimento humano. É, pois, uma aproximação daquilo que Oliveira (2001, p. 12-13) defende sobre desenvolvimento local "como qualidade, ou ancora na cidadania, ou então será apenas sinônimo de uma certa acumulação de bem-estar e qualidade de vida nos âmbitos mais restritos" e, portanto, "comporta tantas quantas sejam as dimensões em que se exerce a cidadania". E onde existe cidadania, as possibilidades de transformar crescimento em desenvolvimento são maiores.

Para tanto, é decisiva a articulação das escalas - horizontais e verticais - para a construção de estratégias de desenvolvimento local e regional. É preciso pensar o local em que o IF está situado, sua territorialidade: perscrutar suas potencialidades, vasculhar as necessidades das populações, tomando como horizonte o quadro

\footnotetext{
${ }^{4}$ Ver Lei N. ${ }^{\circ} 11.892$, inciso I do Art. $6^{\circ}$.
} 
universal. O que significa também ter a coragem de romper com modelos consagrados e ousar, delinear outro caminho, coerente com a institucionalidade proposta. A esse respeito, atuar em escala supralocal é desafiador e complexo, mas, certamente, possibilitará a construção de uma agenda de ações articuladas no sentido do desenvolvimento local e regional. Ao mesmo tempo, há questões que devem ser levantadas. Que desenvolvimento é esse que acontece no local e no regional? Sendo instituições federais, executoras de uma política pública, os IFs são sensíveis à hegemonia de determinados interesses de grupos e classes no Estado? Como realizar o empoderamento do IF pela sociedade? E neste caso, que interesses vão prevalecer?

Essas questões evidenciam a importância do território na concepção e atuação dos IFs (segundo aspecto) e na definição dos horizontes de sua atuação 5 . Do ponto de vista da localização, os critérios seguiram a divisão políticoadministrativa da federação e a delimitação regional do Instituto Brasileiro de Geografia e Estatística - IBGE. No que tange à implantação dos IFs e, posteriormente, à localização dos novos campi oriundos do plano de expansão da Rede Federal, a premissa foi o limite geográfico dos estados federados. Não há nenhum IF com campus fora do estado onde está sua reitoria. Outro critério foi a distribuição de seus campi considerando-se as mesorregiões socioeconômicas dos estados, em razão da natureza das atividades-fim dos institutos nas respectivas regiões. Entretanto, a partir das contribuições de diversos autores apresentados nas seções anteriores, a dimensão apenas geográfica e político-administrativa do território é limitadora e deve ser superada para alcançarmos uma concepção de território como construção histórica sociocultural que ocorre em determinado espaço e tempo, não homogêneo, permeado por conflitos em suas relações sociais e em permanente movimento.

Ainda sobre a questão da territorialidade nos IFs, assume lugar de importância o fato de que essas instituições foram constituídas em rede ${ }^{6}$. A formação da rede se deu em escala nacional, pela referência ao conjunto de instituições federais que atuam na oferta de EPT vinculadas ao Ministério da Educação. A partir desta, no entanto, podem também emergir redes intrarregionais e inter-regionais, e até mesmo em escalas mesorregionais, microrregionais ou em outras escalas específicas. Nesse sentido, o território em rede torna-se mais amplo que o local.

O terceiro aspecto consiste no desafio de estabelecer um diálogo com o território. O IF deve buscar instrumentos para o diálogo com a sociedade, compreendida em sua diversidade social e cultural e diferenciação produtiva, que precisa ser tratada, afirma Bacelar (2009), como a grande potencialidade de que dispomos. É fundamental dialogar com as instâncias municipais e estaduais; sindicatos; setores industriais e comerciais; com as representações oriundas da chamada produção elaborada; os médios e pequenos empreendimentos e movimentos sociais; organizações de bairro; com o trabalhador que sonha ter acesso ao conhecimento, mas que nunca se percebeu com direito à escola.

A política pública se estabelece no compromisso com o universal, aspecto que funda a igualdade na diversidade (social, econômica, geográfica e cultural), e

\footnotetext{
${ }^{5}$ Ver Lei N. ${ }^{\circ} 11.892, \$ 3^{\circ}$ do Art. $2^{\circ}$.

${ }^{6}$ Ver Lei N. ${ }^{\circ} 11.892$, em seu Art. $1^{\circ}$.
} 
ainda, com a articulação entre as políticas (de trabalho e renda, desenvolvimento econômico, ambiental, social e educacional), estabelecendo elos intersetoriais. Como pondera Souza (2006, p. 25), ao afirmar a visão holística nas definições sobre política pública, trata-se de “...uma perspectiva de que o todo é mais importante do que a soma das partes e que indivíduos". Como fazer isso? Como a estrutura organizacional pode assegurar os diversos diálogos? Apenas formando trabalhadores ou também discutindo um projeto de desenvolvimento e fomentando empreendimentos solidários e de médio e pequeno portes?

$\mathrm{E}$, por último, como suporte aos três aspectos mencionados, considera-se a autonomia conferida por lei aos IFs. O conceito de autonomia pressupõe a capacidade de estabelecer normas próprias sobre aquilo que lhe é próprio (BUCCI, 2014), ou seja, aquilo que se refere ao IF, cabe ao próprio IF, em sua construção com a e pela sociedade.

Nos IFs, a questão da autonomia advém de sua natureza jurídica de autarquia e da prerrogativa de criação e extinção de cursos e expedição e registro de diplomas, como também deve-se ao fato de a proposta orçamentária anual ser identificada para cada campus e a reitoria - exceto no que diz respeito a pessoal visto que são os campi que melhor podem definir onde aplicar seus recursos, pois possuem melhores condições de identificar quais os investimentos que atendem efetivamente os interesses locais, na perspectiva do desenvolvimento regional (SILVA, 2009). Ser autônomo, no conjunto dos campi que compõem o Instituto, é perceber que um movimento que um campus faz tem reflexo no outro. Autonomia deve servir para uma relação não sectária, mas solidária. Nesse sentido, perguntase: a autonomia está sendo exercida em nome da natureza institucional, a partir de um regramento, de uma institucionalidade?

A abordagem dos quatro aspectos, finalizando-os com indagações, constitui uma estratégia de realçar as inquietudes com que os autores deste artigo se depararam no decorrer da análise do exercício da gestão. Há uma percepção da existência de hiatos entre a missão institucional e a forma de organização dos processos, tanto do ponto de vista pedagógico como administrativo e da gestão. $O$ "chão de fábrica", ou seja, a realidade traz uma complexidade a que o modelo institucional muitas vezes não consegue responder e, neste caso, corre-se o risco de voltar as costas para ela, enquanto o que se tem a fazer é dar conta desta complexidade da gestão. Daí a importância de se fazer, permanentemente, o exercício crítico a respeito dessas questões.

É importante registrar que a implantação de uma política nacional de base territorial implica desafios que envolvem o confronto entre concepções préestabelecidas e realidades específicas, colocando-as em "xeque". Os IFs, ao se constituírem em rede, o fizeram a partir de determinado perfil institucional que se replicou em todo o País, mas, ao mesmo tempo, cada território é carregado de histórias e singularidades, gerando uma atmosfera de maior ou menor aderência ou ajustes.

Nesse contexto, aborda-se a experiência do IFFluminense, que atua local e regionalmente, e traz, em sua natureza, o compromisso com a regionalização de uma política nacional. Assim, será apresentado o relato de uma experiência em que se incorporou uma escala específica de gestão na constituição do Consup, a de constituição dos Núcleos. 
Experiência de adoção de outra escala territorial: uma aproximação da gestão do IFFluminense

Os IFs se estruturaram sob a justificativa da constituição de uma nova institucionalidade e consideram: o enfoque no desenvolvimento regional, sua articulação com o território, o compromisso com os necessários e possíveis diálogos e sua autonomia conferida por lei. Entretanto, quando a instituição se instala, tornam-se imperativas algumas mudanças, impulsionadas pela percepção empírica de que aquilo que foi idealizado se depara com uma realidade carregada de elementos que escapam ao projetado. É importante reconhecer a necessidade de ajustes, ditados pelo factual, para que possa emergir, efetivamente, a nova institucionalidade. Como consequência, os IFs precisam criar condições, quer de pessoas, materiais, normativas, de infraestrutura, para dar tangibilidade a essa institucionalidade.

Sob esse aspecto, os colegiados existentes nos $\mathrm{IFs}^{7}$ desempenham um papel relevante, pois, na condição de representantes dos diversos segmentos, seus membros têm a responsabilidade de agir em nome das ideias, das iniciativas, por meio de processos formais, que assegurem o funcionamento dos IFs. E isso não é simples, pois envolve as complexidades existentes na articulação das diversas vozes. Acrescente-se a essa incumbência o desafio para que a formação desta instituição não pareça disforme, o que envolve os vários modos de expressão, seja na concepção do projeto político-pedagógico, no material didático produzido, no manual do processo seletivo de estudantes e, principalmente, nas normas de escolha de seus representantes nos colegiados. Enfim, os elementos simbólicos e materiais presentes no interior da instituição e na articulação com os indivíduos, a sociedade e suas representações, devem expressar a singularidade do IF.

De forma geral, guardadas algumas particularidades, nos IFs a constituição de seus colegiados tem como referência predominante os segmentos da comunidade acadêmica (estudantes, professores, técnico-administrativos e egressos), do corpo gestor, dos representantes externos; neste último, específico para o Consup e o Conselho de campus. Há, ainda, no Consup, uma representação do Ministério da Educação.

No Consup do IFFluminense, a distribuição quantitativa das representações se fazia, até março de 2015, com base nos segmentos (de estudantes, professores, técnico-administrativos e corpo gestor) e na fixação de um número de representantes (no caso dos egressos e da sociedade civil), independente de qual campus fossem as representações ${ }^{8}$.

Em princípio, não parecem questionáveis tais critérios. No entanto, a um olhar mais cuidadoso, percebe-se assimetria na formação do Conselho. Por um lado, o Consup desempenha um papel extremamente relevante na gestão dos IFs, sendo a instância maior de deliberação. Silva (2009) afirma sua importância quando

\footnotetext{
7 Os colegiados, de acordo com a Lei $\mathrm{n}^{\circ}$ 11.892, são: Consup, Colégio de Dirigentes, Conselho de Ensino, Pesquisa e Extensão, Conselhos de campus.

${ }^{8}$ Conforme o primeiro Estatuto do IFFluminense (Resolução N. ${ }^{\circ}$ 07/2010), eram 02 representantes de egressos e 06 da sociedade civil. E para as representações dos estudantes, professores, técnicoadministrativos e diretores gerais dos campi, eram 02 representantes de cada segmento (quantitativo definido com base no número de campi).
} 
registra que, em se tratando do Consup de uma instituição de ensino, pesquisa e extensão com atuação verticalizada, do nível básico à pós-graduação, a qualificação política e saberes de seus membros são fundamentais, na medida em que são eles quem definem e referendam as políticas estratégicas para a instituição. Por outro lado, a institucionalidade dos IFs caracteriza-se pela sua atuação no território, em todas as perspectivas já apontadas, a saber: no diálogo imprescindível com a sociedade e na ênfase no desenvolvimento local e regional. Assim, há um desencontro, pois a formação do Conselho não traduz esta angulação para o território e sua composição. Ao seguir o critério das representações por segmento, torna a representatividade do território de atuação do IFFluminense no Conselho meramente "acidental", um "acaso".

Há de se considerar que os tempos de constituição dos campi ocorrem em condições bastantes distintas, de modo que, se respeitadas as regras mais universais de eleição das representações, a tendência é os campi com mais numerosa comunidade acadêmica serem privilegiados, secundarizando ou mesmo sendo mais difícil a representação dos campi com comunidade acadêmica menos numerosa. Como a questão da territorialização é fundamental na matriz identitária dos IFs e de sua missão institucional, preservar princípios que reconheçam e valorizem os diversos territórios na perspectiva da sua inclusão constitui elemento fundante dessas instituições.

O IFFluminense tem sua área de atuação fincada em quatro mesorregiões do Estado, com predominância em duas delas, considerando o número de municípios com campus. De acordo com seu estatuto

\begin{abstract}
Art. $1^{\circ}, \S 5^{\circ}-\mathrm{O}$ Instituto Federal Fluminense possui limite de atuação territorial para criar e extinguir cursos, [...]circunscrito ao Estado do Rio de Janeiro, nas mesorregiões: Noroeste Fluminense; Norte Fluminense, das Baixadas Litorâneas e Metropolitana do Rio de Janeiro. (INSTITUTO FEDERAL FLUMINENSE, 2015).
\end{abstract}

É interessante mencionar, para esta análise, o caso das Escolas de Fronteiras com campi de IFs situados nas regiões de fronteira. Em Santana do Livramento, município do Estado do Rio Grande do Sul, fronteiriço com o Uruguai, o Instituto Federal Sul-Rio-Grandense e a Universidad del Trabajo del Uruguay são responsáveis pela oferta de cursos técnicos binacionais, respectivamente, nos campi Santana do Livramento e Rivera. Como explicar essa experiência se não considerarmos outras escalas, que romperam, inclusive, com limites do território nacional?

A diferença de atributos naturais, econômicos, históricos, sociais e culturais sugere a regionalização do território de atuação dos IFs para além das mesorregiões como também dos municípios. Assim, qual a melhor escala para dar conta desta institucionalidade, em cada situação territorial? Não há pretensão aqui em se dar uma resposta definitiva, até mesmo porque, como argumenta Brandão (2004a, p. 60), deve-se "buscar a escala de observação adequada para a tomada dos fenômenos sobre os quais se deseja intervir". Nesse sentido, considera-se imprescindível construir escalas que correspondam à realidade em que os IFs estão situados, para atuar como ator estratégico para o desenvolvimento das regiões.

Ao discutir a possibilidade de adoção de outras escalas para o desenvolvimento das ações dos IFs, a experiência do IFFluminense, adotando uma forma de constituição do Consup que busca incorporar a representatividade 
territorial quando da renovação dos seus membros para o biênio 2015-2016, demonstra que é possível encorpar a gestão institucional buscando construir estratégias multiescalares.

Assumindo o desafio de traduzir a territorialidade do IFFluminense, de forma a estar contemplada na representatividade do Consup, a reitoria do Instituto apresentou proposta, aprovada na $1^{\text {a }}$ reunião ordinária do Conselho, em 05/02/2015, com nova composição deste Conselho, baseada no conceito de Núcleo, definido como o conjunto de unidades do Instituto, segundo as regiões de localização das unidades. A proposta buscou a valorização de uma escala territorial que pudesse potencializar a articulação e a mobilização dos conselheiros e da comunidade acadêmica, travando maior diálogo com a comunidade em geral, em suas diversas formas de representação.

Assim, o território de atuação do IFFluminense, para efeito de representatividade na composição do Consup, foi redesenhado ${ }^{9}$ em quatro núcleos:

- Núcleo I. Formado pelos campi e unidades localizados nos municípios de Bom Jesus do Itabapoana, Itaperuna, Cambuci e Santo Antônio de Pádua, na mesorregião Noroeste Fluminense, incluindo os territórios das microrregiões de Sto. Antônio de Pádua e de Itaperuna.

- Núcleo II. Formado pelos campi e unidades localizados nos municípios de Campos dos Goytacazes e São João da Barra ${ }^{10}$, na mesorregião Norte Fluminense, abarcando área da microrregião de Campos.

- Núcleo III. Formado pelos campi e unidades localizados nos municípios de Quissamã e Macaé, na mesorregião Norte Fluminense, abarcando área da microrregião de Macaé.

- Núcleo IV. Formado pelos campi e unidades localizados nos municípios de Cabo Frio, na mesorregião Baixadas Litorâneas, microrregião de Lagos; e em Maricá e Itaboraí, na mesorregião Metropilitana, microrregião do Rio de Janeiro.

A representatividade territorial no Consup fica garantida, ainda, no processo de escolha das representações dos segmentos dos estudantes, dos professores e dos servidores técnico-administrativos, pelo qual cada Núcleo poder ter, no máximo, uma representação de cada segmento.

Essa medida busca criar a possibilidade de impulsionar maior mobilização e diálogo entre as comunidades que constituem os núcleos, desde o momento de escolha dos representantes no Consup, que, por estarem apoiados em elementos e processos que caracterizam e diferenciam as regiões, alimentam o debate mais profícuo no Conselho, como reflexo de uma convivência pautada por maior convergência e compreensão das distintas realidades.

A nova composição do Consup trouxe, também, uma ampliação quantitativa e qualitativa de outra ordem. Em relação à representação dos diretores gerais e dos egressos, houve um aumento na representação. E, no caso da sociedade civil, enquanto no formato anterior, eram seis membros retratando uma estrutura social tradicional, ou seja, representações patronais, de empregados e do serviço público, no atual, são oito representantes da sociedade civil organizada e suas expressões, distribuídos em patronais, trabalhadores, setor público e organizações sociais, ficando esta última a ser escolhida por meio de participação livre em chamadas

\footnotetext{
${ }^{9}$ Ver Estatuto do IFFluminense (Resolução N. ${ }^{\circ}$ 12/2015 em www.iff.edu.br).

${ }^{10}$ No Núcleo II, inclui-se a Reitoria do IFFluminense.
} 
públicas. Está previsto ainda, no $\S 6 .^{\circ}$ do artigo $80^{\circ}$ do Estatuto, que os ex-reitores do IFFluminense poderão ser membros do Consup, na condição de ativo, sem direito a voto.

Por contraste, a composição anterior, em que eram apenas definidos os números de representantes por segmentos, além de não assegurar um equilíbrio intercampi, na medida em que poderia inflar a representatividade dos campi maiores, também poderia restringir as condições para formação de conexões intrínsecas. Pela análise comparativa entre as colunas do Quadro 1, pode-se perceber a mudança em favor da representatividade territorial no Consup.

Quadro 1. Composição anterior e atual do Conselho Superior do Instituto Federal Fluminense

\begin{tabular}{|c|c|c|c|c|c|}
\hline \multicolumn{3}{|c|}{ Composição anterior } & \multicolumn{3}{|c|}{ Composição atual } \\
\hline Representação & Membros & $\mathrm{N}^{\circ}$. & Representação & Membros & $\mathrm{N}^{\circ}$. \\
\hline Presidência & Reitor & 01 & Presidência & Reitor & 01 \\
\hline MEC & SETEC & 01 & MEC & SETEC & 01 \\
\hline \multirow{3}{*}{ Segmento } & Discente & 02 & \multirow{3}{*}{ Núcleo I } & Discente & 01 \\
\hline & Docente & 02 & & Docente & 01 \\
\hline & $\begin{array}{l}\text { Técnico- } \\
\text { administrativo }\end{array}$ & 02 & & Técnico-administrativo & 01 \\
\hline \multirow{3}{*}{ Gestão dos campi } & \multirow{3}{*}{ Diretor Geral } & \multirow{3}{*}{02} & \multirow{3}{*}{ Núcleo II } & Discente & 01 \\
\hline & & & & Docente & 01 \\
\hline & & & & Técnico-administrativo & 01 \\
\hline \multirow{4}{*}{ Externa } & Egressos & 02 & \multirow{4}{*}{ Núcleo III } & \multirow[b]{2}{*}{ Discente } & \multirow[b]{2}{*}{01} \\
\hline & $\begin{array}{l}\text { SC: entidades } \\
\text { patronais }\end{array}$ & 02 & & & \\
\hline & $\begin{array}{l}\text { SC: entidades } \\
\text { trabalhadores }\end{array}$ & 02 & & Docente & 01 \\
\hline & $\begin{array}{l}\text { SC: setor público } \\
\text { e/ou empresas } \\
\text { estatais }\end{array}$ & 02 & & Técnico-administrativo & 01 \\
\hline \multirow{3}{*}{\multicolumn{2}{|c|}{-}} & \multirow{3}{*}{-} & \multirow{3}{*}{ Núcleo IV } & Discente & 01 \\
\hline & & & & Docente & 01 \\
\hline & & & & Técnico-administrativo & 01 \\
\hline & - & - & Gestão dos campi & Diretor Geral & 04 \\
\hline \multirow{5}{*}{\multicolumn{2}{|c|}{-}} & \multirow{5}{*}{-} & \multirow{5}{*}{ Externa } & Egressos & 04 \\
\hline & & & & SC: entidades patronais & 02 \\
\hline & & & & $\begin{array}{l}\text { SC: entidades } \\
\text { trabalhadores }\end{array}$ & 02 \\
\hline & & & & $\begin{array}{l}\text { SC: setor público e/ou } \\
\text { empresas estatais }\end{array}$ & 02 \\
\hline & & & & SC: Organizações sociais & 02 \\
\hline \multicolumn{2}{|c|}{ TOTAL } & 18 & \multicolumn{2}{|r|}{ TOTAL } & 30 \\
\hline
\end{tabular}

Legenda: SC = Sociedade Civil.

Fonte: resoluções Consup IFFluminense N. ${ }^{\circ} 07 / 2010$ e N. ${ }^{\circ}$ 12/2015.

Não se tem notícia de uma configuração escalar semelhante a esta entre os IFs. Ainda é cedo para ser avaliada em seus resultados, porém tais mudanças possibilitaram, no decorrer do processo de escolha dos representantes, um diálogo maior entre as pessoas de cada núcleo. Como efeito, tais mudanças e seus 
resultados podem contribuir para avanços em outros colegiados, não apenas na forma e conteúdo, mas no sentido de que outros recortes escalares possam ser realizados. A importância da experiência extrapola a especificidade dos Núcleos no Consup. Desenhada pelo IFFluminense, ela se insere no desafio de vincular o IF às ações integradas, locais e regionais, de desenvolvimento. Mais do que a experiência em si, o que importa é o reconhecimento de que é decisivo enfrentar o debate do papel das escalas espaciais para um maior entendimento da realidade e melhor intervenção nesta realidade.

É importante destacar que essa iniciativa diz respeito, ainda, à tentativa de superar uma diferenciação que, muitas vezes, pode reproduzir uma discriminação e não uma distinção como sinônimo de reconhecimento às diversas identidades (do território) presentes no IF. A adoção do conceito de núcleo produziu um diálogo entre as unidades que compõem cada núcleo, que devem aliar suas particularidades aos princípios e diretrizes que compõem a natureza institucional, construindo redes de solidariedade e troca para além da competição e conflito.

É fundamental não ter um olhar sobre os IFs como algo homogêneo, na mesma medida em que, ao considerar sua diversidade, se faça como valorização de uma natureza mais republicana e mais democrática. Afinal, no contexto da atuação dos IFs, não se pode considerar que uma determinada região e seus problemas e demandas se sobreponham ou sejam mais importantes do que as outras; ainda que não se possa desconsiderar que prioridades podem ser "negociadas" no coletivo.

É importante, pois, a construção de escalas alternativas para aproximar os IFs do seu território, principalmente em se tratando de um modelo institucional ainda em consolidação, que pode contribuir para propostas de regionalização de seu território, sem abandonar as construções escalares previstas na legislação.

\section{Considerações finais}

Com uma tipologia singular e objetivos voltados para uma intervenção mais contributiva para a redução das desigualdades regionais, aos IFs foi estabelecido uma atribuição de forte envolvimento com o território, o que lhe confere a responsabilidade de assumir seu lugar como ator estratégico nos debates e nos rumos do desenvolvimento de sua região.

A perspectiva do artigo foi mostrar o potencial de alcance dessa política educacional, por meio da interiorização e da regionalização desse equipamento público que guarda estreita relação com o desenvolvimento, por atuar na formação profissional, na pesquisa aplicada e na democratização do acesso ao conhecimento com visão estratégica.

Entretanto, na criação e na implantação dos IFs, tomando como referência o IFFluminense, as evidências empíricas mostraram que há lacunas entre a missão institucional vinculada ao desenvolvimento do território e a forma de organização dos processos pedagógico, administrativo e de gestão. Isso levou à adoção de escala específica para subsidiar o trabalho da gestão do Instituto, a fim de superar os espaços vazios que se formaram e se formam ao longo da atuação institucional. Nesse sentido, considera-se importante o acompanhamento desse processo de escolha dos conselheiros da comunidade acadêmica com a adoção do conceito de Núcleo na composição do Consup, que pode ser realizado pelo próprio Conselho e 
suas representações, a fim de avaliar, por exemplo, se a flexibilidade que as escalas oferecem pode diminuir o descompasso entre o aparato normativo-institucional e as atribuições do IFFluminense, o que ganha relevância em se tratando de políticas públicas.

A análise desenvolvida neste artigo voltou-se, especificamente, para a assimetria resultante das representações das comunidades dos campi no Conselho. No entanto, é preciso também chamar atenção para a importância de estudos futuros sobre o equilíbrio que deve haver entre as representações internas e externas no Conselho, sem os quais as próprias demandas e o controle da sociedade podem ter prejuízos na pauta, não se alcançando a escuta efetiva. Tal sugestão é porque no Consup prevalecem, numericamente, os membros que estão ligados organicamente à instituição. Para os autores, essa questão, no que pese não ter sido objeto deste artigo, tem extrema importância e, neste sentido, deve ser observada do ponto de vista de debates na perspectiva de aperfeiçoamentos futuros desta representação.

Obviamente, que as questões levantadas neste artigo, assim como outras que deverão surgir, devem fomentar um ambiente profícuo ao debate e à participação dos envolvidos. Há uma grande e urgente demanda pela construção de pontes entre a institucionalidade dos IFs e os mecanismos e instrumentos de gestão a fim de projetar os Institutos em seu território e procurar entender de que maneira e o quanto a dinâmica socioeconômica deste território vem sendo apropriada pela instituição e retratada em suas iniciativas. O que não se esgota nos instrumentos de gestão, mas interfere nos projetos pedagógicos e nos conjuntos das atividades da instituição.

\section{REFERÊNCIAS}

BACELAR, Tânia. Entrevista com Tânia Bacelar, especialista em desenvolvimento regional. Revista Rumos, Brasília, 2009, 9 pp. Disponível em: < http://planejamento.rs.gov.br/upload/arquivos/201512/15134038-20130730160202920130401115228 entrevista-taniabacelar-revista-rumos.pdf>. Acesso em: 28 set. 2017.

. Tendências do Desenvolvimento Regional recente no Brasil. In:

BRANDÃO, C.A.; SIQUEIRA, H. (Orgs.). Pacto Federativo, integração nacional e desenvolvimento regional. São Paulo: Editora Fundação Perseu Abramo, 2013. p. 3951.

BRANDÃO, C. A. Teorias, estratégicas e políticas regionais e urbanas recentes: anotações para uma agenda do desenvolvimento territorializado. Revista Paranaense de Desenvolvimento, Curitiba, n.107, p.57-76, jul./dez. 2004 a.

. O processo de subdesenvolvimento, as desigualdades espaciais e o "jogo das escalas". Superintendência de Estudos Econômicos e Sociais da Bahia. Desigualdades Regionais. Salvador: SEl. 2004b. Série Estudos e Pesquisas, n. 67, p. 9-37.

- A reafirmação do nacional e as possibilidades de estratégias e políticas de desenvolvimento e suas escalas espaciais. In: . Território e 
desenvolvimento: as múltiplas escalas entre o local e o global. 2. ed. Campinas: Editora da Unicamp, 2012. Cap. 5.

. Crises do(s) Capitalismo(s) e os espaços produzidos nas escalas mundial, nacional e regional. In: Crises do Capitalismo, Estado e Desenvolvimento Regional. Sta. Cruz do Sul;RS: EDUNISC, 2014a. p.. 9-39.

. Avançamos na PNDR II, mas falta transformá-la em uma estratégia de Estado. Revista Política e Planejamento Regional, Rio de Janeiro, v. 1, n. 2, p. 339344, dez. 2014b.

BRASIL. Chamada Pública MEC/SETEC n. 002, de 12 de dezembro de 2007, Chamada Pública de Proposta para constituição dos Institutos Federais de Educação, Ciência e Tecnologia. Brasília, 2007a.

- Ministério da Educação. O Plano de Desenvolvimento da Educação: razões, princípios e programas. Brasília, MEC, $2007 \mathrm{~b}$.

. Lei $\mathrm{n}^{\circ} 11.892$, de 29 de dezembro de 2008. Cria os Institutos Federais de Educação, Ciência e Tecnologia, e dá outras providências. Diário Oficial [da] República Federativa do Brasil. Poder Executivo, Brasília, DF, 30 dez. 2008.

BUCCI, M.P.D. Colegiados e Democracia na Gestão Pública. In: CAPACITAÇÂO DE COLEGIADOS E CONSELHOS, 2014. Disponível em:

<https://www.youtube.com/watch?v=kOGu1xbheGg\&index=562\&list=UUD4fOQllod KrVKO_8fScOEQ>. Acesso em: 23 jul. 2016.

CRUZ, José Luis Vianna. Espaço social, ambiente construído e reprodução social. Série UCAM-Região: UCAM-Campos, Campos dos Goytacazes, ano III, n. 10, mai.2007, 36pp.

DINIZ, Clélio Campolina. A busca de um projeto de nação: o papel do território e das políticas regional e urbana. Revista EconomiA, Brasília, v. 7, n. 4, p. 1-18, dez. 2006.

.O risco da relitorialização. Carta Capital, n. 705, p. 37, 2012.

HADDAD, Fernando. Haddad destaca expansão do ensino superior no Bom Dia Ministro [set. 2011]. Programa Bom dia Ministro. Brasília: Empresa Brasileira de Comunicação (EBC). [Sonora: 44'15"'].

HARVEY, D.A. A transformação política-econômica do capitalismo do final do século $X X . \ln :$ . Condição pós-moderna. São Paulo: Edições Loyola, 1992, p. 115184.

INSTITUTO FEDERAL FLUMINENSE. Estatuto do Instituto Federal Fluminense. Campos dos Goytacazes, 2015. 
OLIVEIRA, Francisco. Aproximações ao enigma: o que quer dizer desenvolvimento local? São Paulo, Polis: Programa Gestão Pública e Cidadania/EAESP/FGV, 2001. 41pp.

ORTIGARA, Claudino. Políticas para a educação profissional no Brasil: os Institutos Federais de Educação, Ciência e Tecnologia e a educação integral. Pouso Alegre: IFSul de Minas, 2014.

PIQUET, Rosélia. Indústria e território no Brasil contemporâneo. Rio de Janeiro: Garamond, 2007.

RAFFESTIN, Claude. Por uma geografia do poder. Tradução de Maria Cecília França. São Paulo: Ática, 1993.

SANTOS, Milton. A natureza do espaço. Técnica e tempo. Razão e emoção. São Paulo: Ed. HUCITEC, 1997.

. O retorno do território. In: Editora da Universidade de São Paulo, 2008, p. 137-144. . Da totalidade ao lugar. São Paulo:

SILVA, C. J. R. Institutos Federais lei 11.892, de 29/11/2008: comentários e reflexões / organização. Natal: IFRN, 2009.

SILVEIRA, María Laura. Ao território usado a palavra: pensando princípios de solidariedade socioespacial. In: VIANA, A. L. d’Á; IBAÑEZ, N.; ELIAS, P.E.M. (Org.). Saúde, Desenvolvimento e Território. São Paulo: Editora Hucitec, 2009. p. 127-148.

SIQUEIRA, H. Desenvolvimento regional recente no Brasil. Rio de Janeiro: E-papers, 2010, cap. 3 .

. Dinâmica regional brasileira (1990-2012). In: BRANDÃO, C.A.; SIQUEIRA, H. (Orgs.). Pacto Federativo, integração nacional e desenvolvimento regional. São Paulo: Editora Fundação Perseu Abramo, 2013. p. 73-86.

SOUZA, Celina. Políticas públicas: uma revisão da literatura. Sociologias. Porto Alegre, n. 16, dez. 2006. 
José Luis Vianna da Cruz. Pós-doutorado em Desenvolvimento Territorial e Políticas Públicas (UFRRJ); Doutor em Planejamento Urbano e Regional (UFRJ/IPPUR); mestre em Planejamento Urbano e Regional (UFRJ/IPPUR); especialização em Planejamento do Desenvolvimento Regional (Universidade de Ciências Humanas e Tecnologia, Lille1, França (PROGRAMA ERASMUS, da UE) e Graduado em Ciências Sociais (UFRJ). Professor Associado, nível 3, aposentado em maio de 2014, da Universidade Federal Fluminense e professor permanente e Coordenador de Pesquisa do Mestrado e do Doutorado em Planejamento Regional e Gestão de Cidades, da Universidade Candido Mendes/Campos dos Goytacazes. joseluisvianna@uol.com.br

Carla Nogueira Patrão Aquino. Doutoranda do Programa de Pós-Graduação em Planejamento Regional e Gestão da Cidade e Mestre em Economia Empresarial pela Universidade Cândido Mendes de Campos; Graduada em Serviço Social pela Universidade Federal Fluminense e em Administração pela Universidade Cândido Mendes. Atualmente ocupa o cargo de Assistente Social no Instituto Federal de Educação Ciência e Tecnologia Fluminense. cnpatrao@gmail.com 